\title{
Pituitary and systemic autoimmunity in a case of intrasellar germinoma
}

\author{
Angelika Gutenberg · Jennifer J. Bell · Isabella Lupi · Shey-Cherng Tzou • \\ Melissa A. Landek-Salgado · Hiroaki Kimura · Jack Su • \\ Lefkothea P. Karaviti · Roberto Salvatori · Patrizio Caturegli
}

Published online: 26 May 2009

(C) Springer Science+Business Media, LLC 2009

\begin{abstract}
Germinomas arising in the sella turcica are difficult to differentiate from autoimmune hypophysitis because of similar clinical and pathological features. This differentiation, nevertheless, is critical for patient care due to different treatments of the two diseases. We report the case of an 11-year-old girl who presented with diabetes insipidus and growth retardation, and was found to have an intra- and supra-sellar mass. Initial examination of the
\end{abstract}

Angelika Gutenberg and Jennifer J. Bell contributed equally.

A. Gutenberg

Department for Neurosurgery, Georg August University

Göttingen, Göttingen, Germany

J. J. Bell · J. Su · L. P. Karaviti

Department for Pediatrics, Texas Children's Hospital, Houston,

TX, USA

I. Lupi

Department of Endocrinology, University of Pisa, Pisa, Italy

S.-C. Tzou - M. A. Landek-Salgado · H. Kimura - P. Caturegli Department for Pathology, Johns Hopkins University, Baltimore, MD, USA

R. Salvatori

Division of Endocrinology, Department of Medicine, Johns

Hopkins University, Baltimore, MD, USA

P. Caturegli

Feinstone Department of Molecular Microbiology and Immunology, The Johns Hopkins Bloomberg School of Public

Health, Baltimore, MD, USA

P. Caturegli $(\square)$

Department for Pathology, Johns Hopkins University, Ross Building, Room 632, 720 Rutland Avenue, Baltimore, MD 21205, USA

e-mail: pcat@jhmi.edu pituitary biopsy showed diffuse lymphocytic infiltration of the adenohypophysis and absent placental alkaline phosphatase expression, leading to a diagnosis of hypophysitis and glucocorticoid treatment. Because of the lack of clinical and radiological response, the pituitary specimen was reexamined, revealing this time the presence of scattered c-kit and Oct4 positive germinoma cells. The revised diagnosis prompted the initiation of radiotherapy, which induced disappearance of the pituitary mass. Immunological studies showed that the patient's serum recognized antigens expressed by the patient's own germinoma cells, as well as pituitary antigens like growth hormone and systemic antigens like the Sjögren syndrome antigen B and alpha-enolase. The study first reports the presence of pituitary and systemic antibodies in a patient with intrasellar germinoma, and reminds us that diffuse lymphocytic infiltration of the pituitary gland and pituitary antibodies does not always indicate a diagnosis of autoimmune hypophysitis.

Keywords Germinoma - Hypophysitis . Pituitary antibodies . Autoimmunity

\section{Introduction}

Germinomas of the brain are rare, representing between 0.4 and $3.4 \%$ of all primary intracranial tumors [1]. They affect predominantly pre-pubertal children [2], and localize more often to the pineal gland or the suprasellar region [2,3], although bifocal lesions are also described [4]. Clinically, sellar germinomas present with a triad of diabetes insipidus, hypopituitarism (most commonly GH deficiency), and visual disturbances (both in acuity and fields). Serologically, germinomas of the brain are usually (85-90\%) negative for beta human chorionic gonadotropin $(\beta$-hCG) 
[1] and alpha-fetoprotein. Pathologically, germinomas feature a characteristic large cell having a centric nucleus with one or more prominent nucleoli surrounded by a clear and abundant cytoplasm (so-called fried-egg appearance). In addition, these tumors contain numerous infiltrating lymphocytes. In the majority $(75 \%)$ of cases, infiltrating lymphocytes are seen side-by-side to nests of neoplastic cells, establishing a two-cell pattern. In the remaining minority (25\%), lymphocytes largely outnumber few isolated neoplastic cells, which therefore become much more difficult to identify [5]. Sellar germinomas enter most commonly in the differential diagnosis of suprasellar masses, together with craniopharyngiomas, Rathke cleft cysts, arachnoid cysts, pituitary adenomas, pituitary metastasis, and Wegener granulomatosis. Occasionally, sellar germinomas localize within the sella turcica and thus enter in the differential of other pituitary lesions rich in lymphocytes, such as lymphocytic hypophysitis.

Hypophysitis can be primary or secondary to systemic or local lesions, such as Rathke's cleft cyst, craniopharyngioma, or germinoma [6]. Primary hypophysitis is caused by an autoimmune reaction directed against the pituitary gland, which becomes pathologically infiltrated by lymphocytes. Primary lymphocytic or autoimmune hypophysitis, abbreviated here as $\mathrm{AH}$, is more common in women during the fourth decade of life [6], but rare in children. Only 25 cases have been reported in patients $<18$ years old at the time of presentation [7].

During the past 10 years, nine cases of lymphocytic hypophysitis secondary to a germinoma initially misdiagnosed as primary $\mathrm{AH}$ have been reported [8-16]. In some patients, the initial diagnosis originated from a clinical and radiological suspicion of hypophysitis, later disproved upon pathological examination [13]. In other patients, a germinoma was suspected clinically but the first pathological examination failed to reveal germinoma cells because of the dense lymphocytic infiltrate [8-11, 16].

We report here an additional patient with an intra-sellar and supra-sellar germinoma initially misdiagnosed and treated for $\mathrm{AH}$, and describe the immunological findings as related to antibodies recognizing pituitary and extra-pituitary antigens.

\section{Case report}

History and clinical examination

An 11-year-old girl was referred for blurred vision, fatigue, polyuria and polydipsia of 18 months duration. Height and body weight were at the 10th and 3rd percentile, respectively, and no pubertal development (Tanner I) was present. Her medical and family history was unremarkable.
Ophthalmological examination showed decreased visual acuity and bitemporal inferior quadrantanopia with diffuse bilateral optic pallor. Baseline assessment of pituitary hormones revealed central hypothyroidism (low free $\mathrm{T} 4$ of $0.4 \mathrm{pmol} / \mathrm{L}$ with inappropriately normal TSH of 2.24 $\mu \mathrm{IU} / \mathrm{mL}$ ), decreased serum IGF-1 (34 ng/mL), and slightly increased prolactin $(23.2 \mathrm{ng} / \mathrm{mL})$. Gonadotropins were in the pre-pubertal range $(\mathrm{LH}<0.2 \mathrm{mIU} / \mathrm{mL}$ and FSH $<0.7 \mathrm{mIU} / \mathrm{mL})$. Serum AFP $(6.2 \mathrm{ng} / \mathrm{mL})$ and $\beta$-hCG $(<0.2 \mathrm{mIU} / \mathrm{mL})$ were negative. Serum cortisol rose only to $11.2 \mu \mathrm{g} / \mathrm{dL}$ after administration of $1 \mu \mathrm{g}$ of ACTH, indicating a partial adrenal insufficiency. Serum and urine electrolytes were normal. She was diagnosed with central diabetes insipidus based on the clinical presentation and response to DDAVP, and treated with desmopressin nasal spray. Anterior pituitary hormones were replaced.

Neuroimaging studies

Cranial MRI (1.5 Tesla magnet) showed an intra- and supra-sellar mass measuring $22 \times 16 \times 17 \mathrm{~mm}$ (Fig. 1a). The mass compressed the optic chiasm, extended minimally into the hypothalamus and down into the pituitary with no visible posterior pituitary bright spot. The mass was iso-hypointense on T1 and T2 weighted images, and heterogeneous on $\mathrm{T} 2$ weighted images without cystic components or focal areas of decreased signal suggestive of calcification. The mass markedly enhanced after gadolinium injection; it remained clearly distinct from the cavernous sinuses, although caused a slight bowing of the supraclinoid portion of both internal carotid arteries with normal flow void. No other abnormalities were identified. Preoperatively, craniopharyngioma was the favored diagnosis, although germinoma and granulomatous entities such as sarcoidosis were also included in the differential.

Pituitary surgery, pathology and postoperative course

A pituitary biopsy was obtained through a fronto-temporal craniotomy approach. Pathological examination of the biopsy showed an anterior pituitary lobe heavily infiltrated by mononuclear cells, with extensive loss of the normal endocrine cells and acinar architecture (Fig. 2a). Immunostainings revealed an equal mixture of B (CD79 positive, Fig. 2b) and T (CD3 positive, data not shown) lymphocytes, and absent placental alkaline phosphatase (PLAP) or $\beta$-hCG expression (data not shown). No immunostainings for c-Kit or Oct4 were performed because germinoma cells were not evident, and thus germinoma was not suspected. A diagnosis of $\mathrm{AH}$ was made and the patient began immediately an intravenous steroid pulse therapy (methylprednisolone, $30 \mathrm{mg} / \mathrm{kg}$ over $2 \mathrm{~h}$ for 3 days), followed by oral prednisone ( $2 \mathrm{mg} / \mathrm{kg} /$ day) for 2 weeks, tapering the 

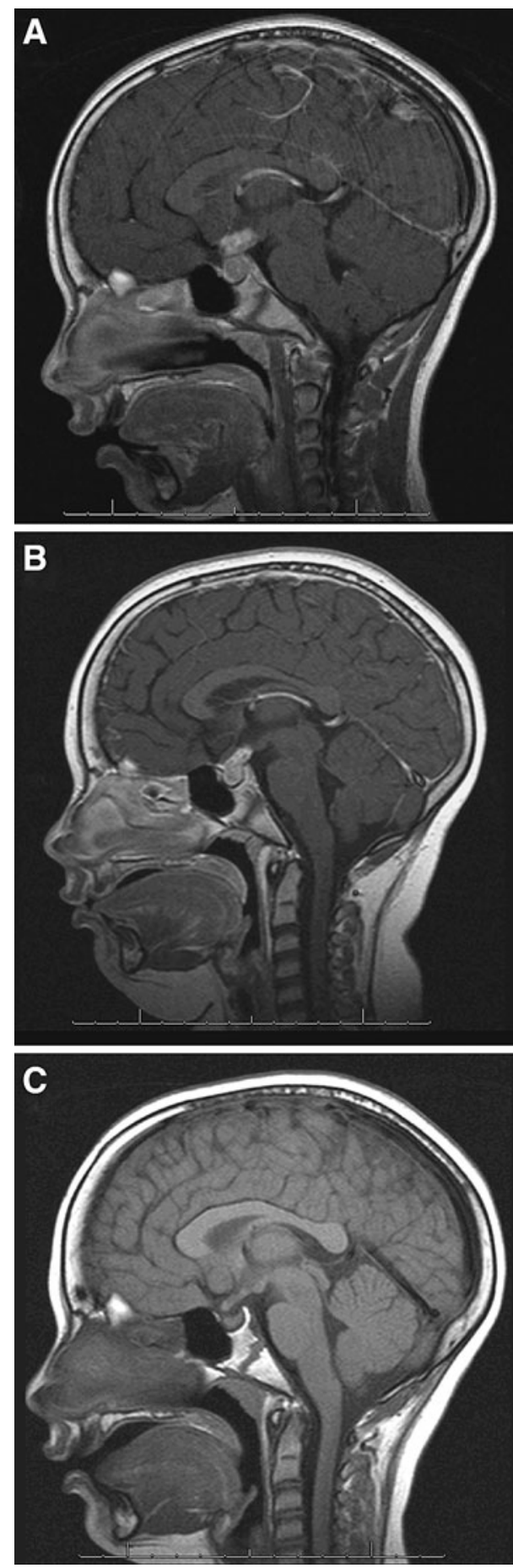

Fig. 1 Cranial MRI images. Sagittal T1 post-contrast images showing the sellar and supra-sellar mass at diagnosis (a), after glucocorticoid treatment (b), and after radiotherapy (c)

dose in 6 weeks. After such treatment, MRI showed only a marginal decrease in the size of the mass (Fig. 1b), and visual fields worsened rather than improved. The initial diagnosis of $\mathrm{AH}$ was, thus, questioned, prompting a reexamination of the pituitary biopsy. This second pathological analysis showed in the anterior pituitary single, large, round cells with prominent nucleoli and abundant clear cytoplasm (Fig. 2c), amongst the dense lymphoid infiltrate. The diagnosis of germinoma was established by demonstrating that these large cells were positive for c-Kit (Fig. 2d) and Oct4 (data not shown).

\section{Radiation therapy and follow-up}

The girl was treated promptly with radiation therapy, using the most conformal plan possible to spare the normal adjacent brain. She received 25.2 Co Gy equivalent to the ventricular region and then a cumulative dose of $41.4 \mathrm{Co}$ Gy equivalent to the area of concern. After radiation therapy, the visual acuity and the right visual field defect and optic nerve pallor stabilized, whereas the left temporal visual field defect disappeared. One year after completion of the proton therapy, cranial MRI showed resolution of the suprasellar mass, thickening of the optic chiasm without definite residual tumor, and a still absent posterior pituitary bright spot (Fig. 1c). Anterior and posterior pituitary function never recovered.

\section{Methods and results}

Recognition of pituitary antigens

by immunofluorescence

The patient's serum was tested for the presence of pituitary antibodies by indirect immunofluorescence, using Macaca mulatta pituitary as the substrate [17]. No pituitary antibodies were found using this method (data not shown), which is known to have low sensitivity and specificity [18].

Recognition of pituitary and systemic antigens by immunoblotting

To increase the sensitivity of pituitary antibody detection, the patient's serum was reacted against normal human pituitary cytosolic proteins, separated by 2-dimensional (2D) gel electrophoresis and blotted onto nitrocellulose membranes as described [17]. The membranes of three $\mathrm{pH}$ ranges (4-5, 5-6, and 6-7) were incubated overnight with the patient's serum diluted 1:100, and the antibody binding detected by chemiluminescence as described [17]. After exposure of the film, the membranes were stripped and incubated in the same fashion with the sera of a known patient with primary AH. Unique protein spots recognized by the germinoma patient were excised from the gel, digested with trypsin, and sequenced using MALDI-TOF mass spectrometry. The germinoma serum recognized six unique protein spots not detected by the $\mathrm{AH}$ serum, in the 
Fig. 2 Pituitary histopathology. a Frozen section of the pituitary biopsy showing a marked mononuclear cell infiltration of the anterior pituitary. b A pan-B cell staining (CD79) shows the heavy infiltrate of $\mathrm{B}$ lymphocytes (similar pattern was obtained using CD3 for T lymphocytes, data not shown). c H\&E staining of the formalinfixed pituitary biopsy, showing a few germinoma cells (inset). d c-Kit staining clearly highlights the germinoma cells
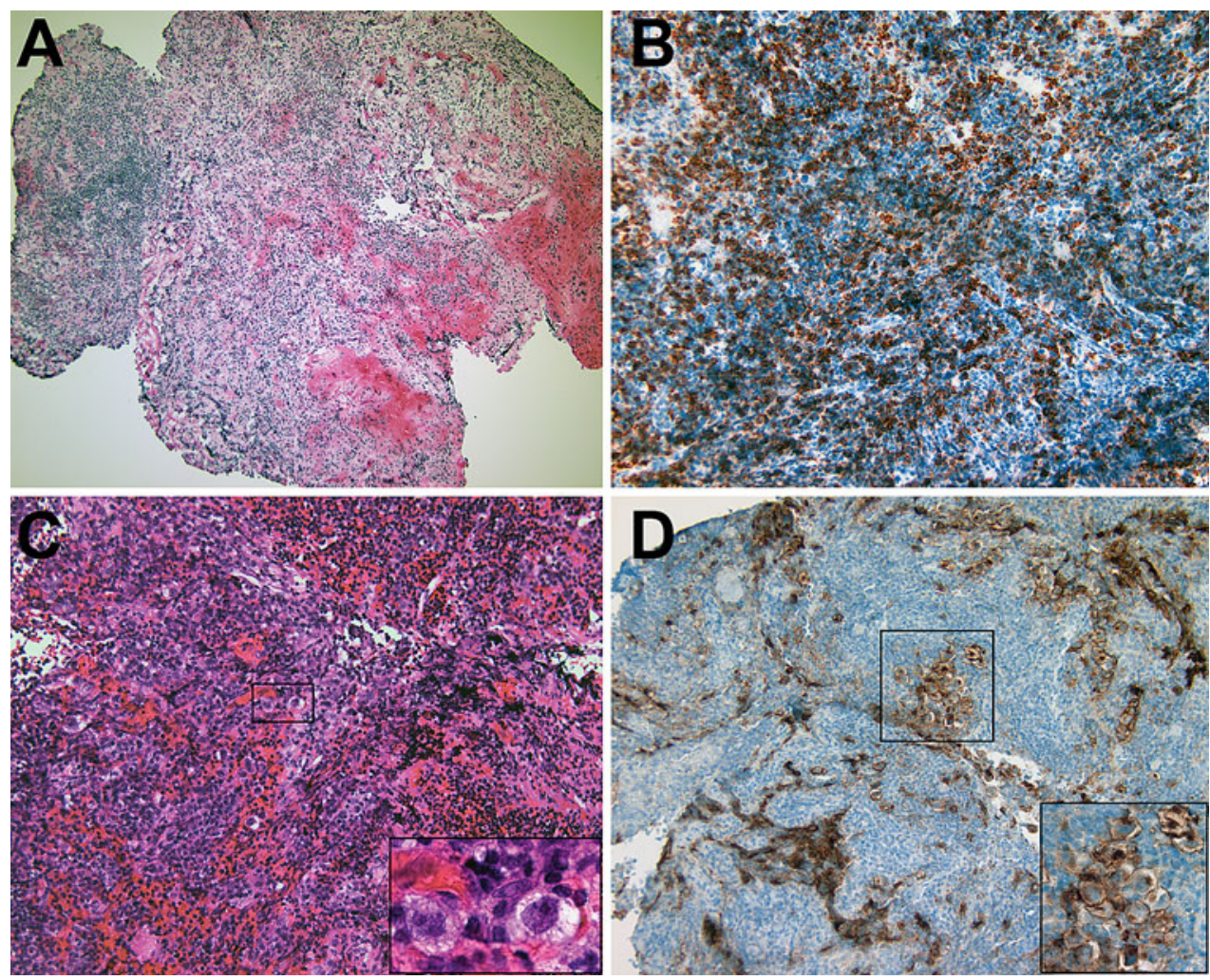

Fig. 3 2-D gel electrophoresis and immunoblotting. Panels a and $\mathbf{b}$ represent the Coomassie blue staining of 2-D gels prepared from human pituitary cytosolic proteins, in the $\mathrm{pH}$ range from 5 to 6 (a) and 6 to 7 (b). c, d Show the corresponding immunoblotting, after the gels were transferred to nitrocellulose membranes and probed using the serum from the germinoma patient
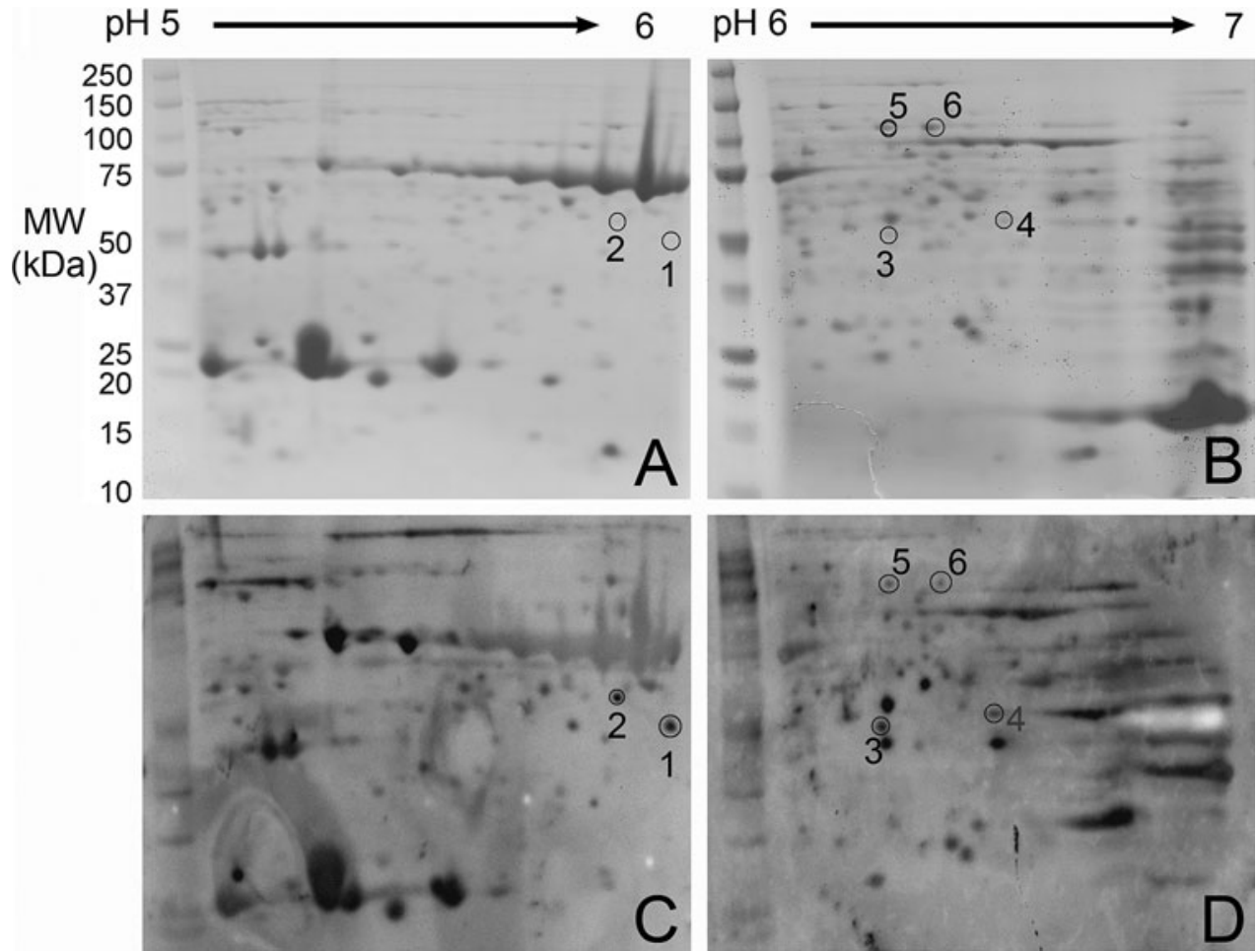

pH ranges from 5 to 6 (Fig. 3c) and 6 to 7 (Fig. 3d). These spots contained both proteins preferentially expressed in the pituitary gland, such as growth hormone, and systemic proteins like the Sjögren's syndrome autoantigen B (La autoantigen) (Table 1). Accuracy of mass spectrometry identification was confirmed by 1-dimensional gel electrophoresis and immunoblotting using a recombinant La protein (Fig. 4). The patient's serum recognized the 


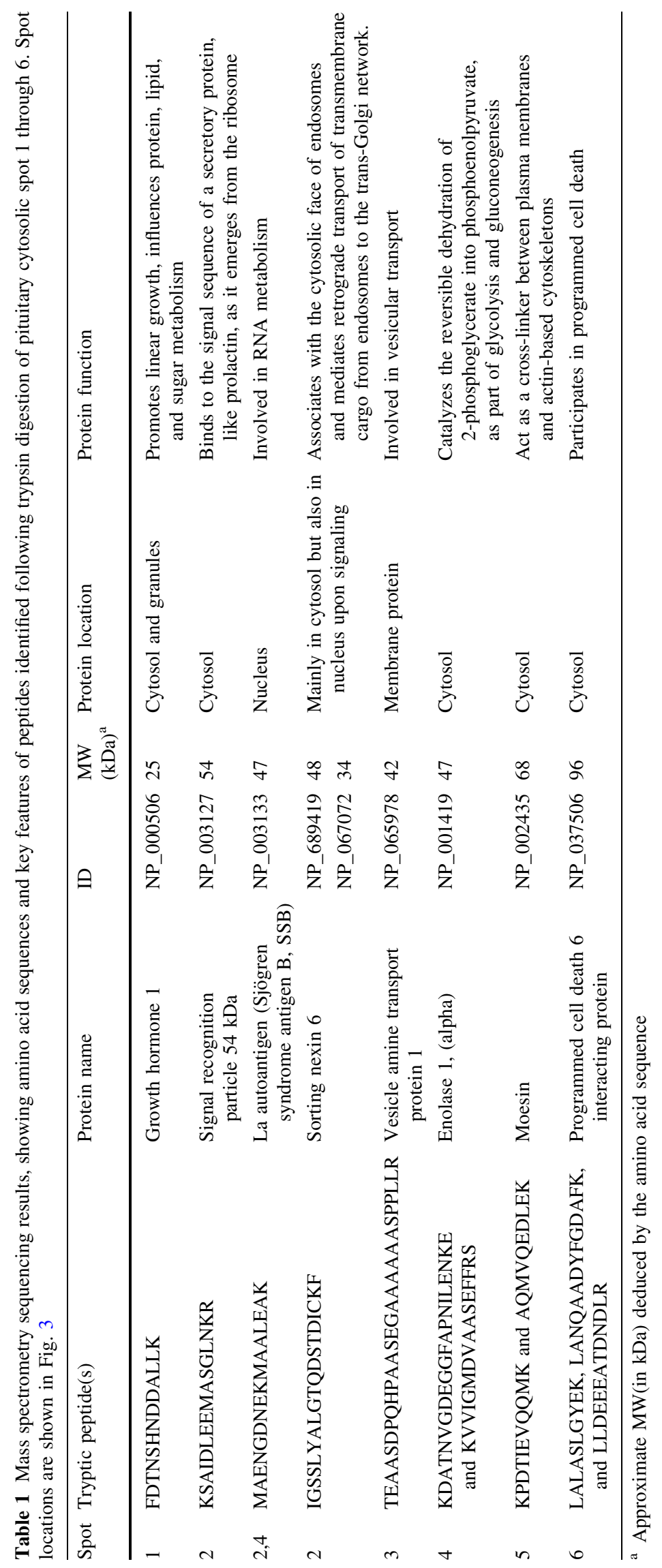




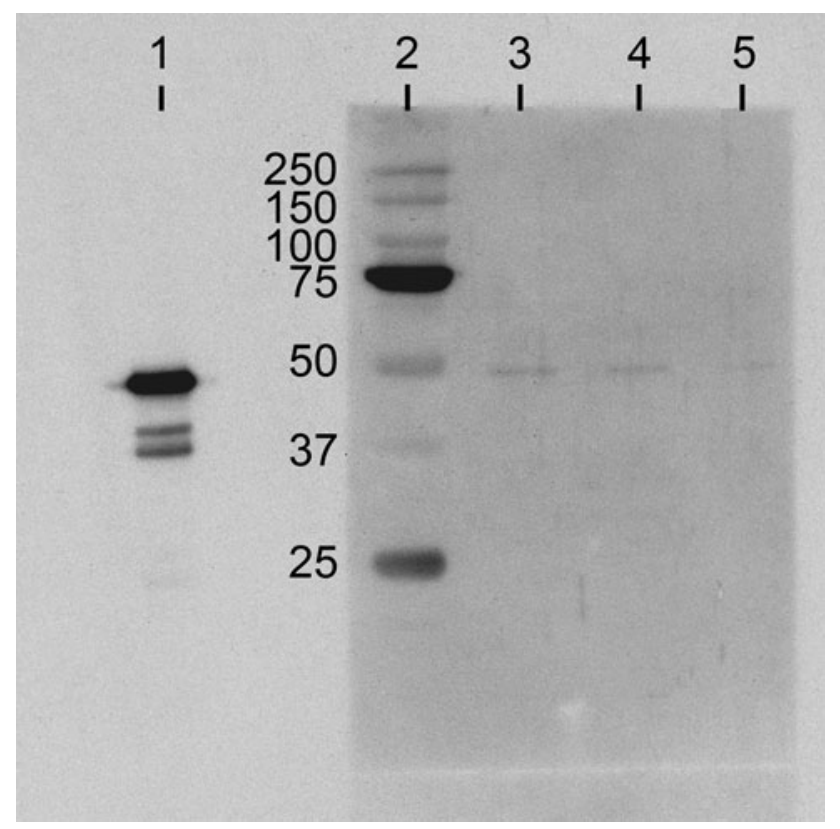

Fig. 4 1-D gel electrophoresis and immunoblotting. The gel showed that the germinoma patient's serum recognized La recombinant protein (added in decreasing concentration from lane 3 to 5). Lane 1 is the positive control using the serum from a lupus patient known to have La autoantibodies

Sjögren syndrome La protein (lanes 3, 4, and 5), similarly to the serum of a patient with systemic lupus erythematosus known to have La autoantibodies (lane 1).

Recognition of germinoma cell antigens by immunohistochemistry

Once the diagnosis of germinoma was established, we asked whether germinoma cells were antigenic and recognizable by the patient's own antibodies. We thus incubated the patient's serum with the patient's pituitary gland biopsy. Pituitary sections ( $3 \mu \mathrm{m}$-thick) prepared from the formalin biopsy were deparaffinized, re-hydrated, and incubated with hydrogen peroxide to block endogenous peroxidase activity. Sections underwent microwave antigen retrieval in a $0.1 \mathrm{mmol} / \mathrm{L}$ citrate buffer for $18 \mathrm{~min}$, and then overnight incubation at $4^{\circ} \mathrm{C}$ with undiluted patient's serum. After proper washing, sections were treated for $1 \mathrm{~h}$ at room temperature with a biotinylated goat anti-human IgG (diluted 1:500, Jackson Immunoresearch), and then with peroxidase-labeled streptavidin. Sections were finally developed with 3-3'-diaminobenzidine (Sigma, USA) chromogen, and counterstained with hematoxylin. In addition to the expected strong staining of the numerous IgG-producing plasma cells that infiltrated the patient's pituitary, the patient's serum also recognized antigens expressed on the membrane and cytoplasm of the large neoplastic germinoma cells (Fig. 5).

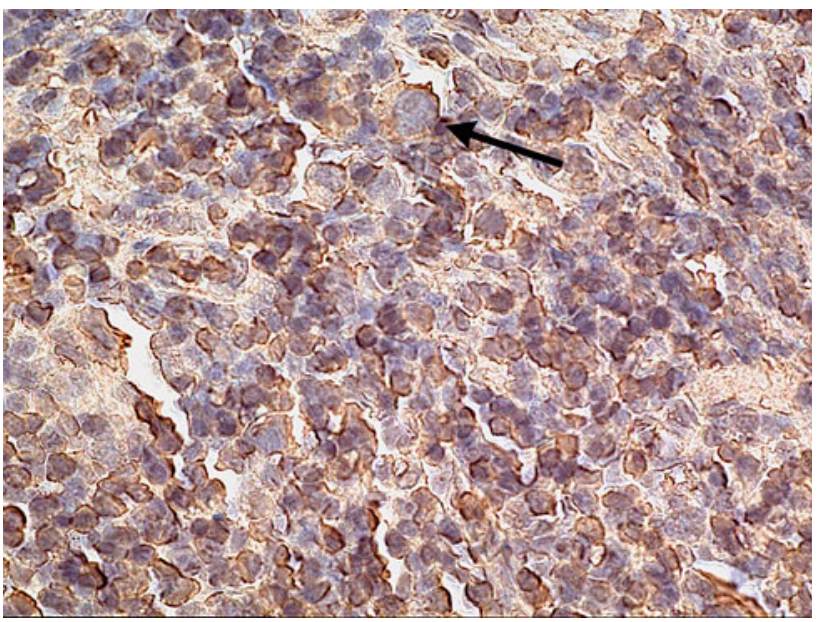

Fig. 5 Immunohistochemistry performed using the patient's own pituitary biopsy and serum. The serum contains antibodies that recognize the large germinoma tumor cells (arrow), among the heavy lympho-plasmacytic infiltrate

\section{Discussion}

The present case report emphasizes the difficulties sometimes encountered in establishing the correct etiology of non-functioning pituitary masses. These masses share similar clinical presentations and radiological findings, and often a similar natural history. In both sellar germinomas and $\mathrm{AH}$, in fact, the hypopituitarism can precede for years a visible pituitary mass [8, 19], so that prolonged symptomatic periods prior to diagnosis are common [2].

In addition to the similarities indicated above, germinomas and $\mathrm{AH}$ can share similar pathological findings. $\mathrm{AH}$ is characterized pathologically by a diffuse infiltration of the pituitary gland with mononuclear cells, predominantly lymphocytes, which disrupt the normal acinar architecture and destroy the endocrine cells. A similar lymphocytic infiltration can also be seen in germinomas, and sometimes it is so marked to render the identification of the neoplastic germinoma cells very challenging. It is therefore not unusual for intrasellar germinomas to be misdiagnosed as $\mathrm{AH}[9,20]$.

Germinomas are highly immunogenic tumors, showing perhaps the highest degree of tumor infiltrating lymphocytes among human neoplasias. Tumor infiltrating lymphocytes have been characterized by immunohistochemistry [21], and are known to favorably affect the clinical outcome of germinomas [5, 22]. Tumor infiltrating lymphocytes are present independently of the anatomic location of the germinoma [23] and despite a low or absent expression of major histocompatibility class I molecules [24].

The reason for this rich lymphoid infiltrate in germinomas, however, remains unknown. We postulated that germinoma cells express a variety of antigens, some of which are never seen by the host immune system, and thus 
capable of initiating a polyclonal immune response. In keeping with this hypothesis, we showed that the patient's germinoma cells, located within her pituitary gland, were recognized by the patient's own serum, indicating the existence of germinoma-specific autoantigens. The patient's serum also contained autoantibodies recognizing numerous proteins present in the pituitary. Some proteins, like growth hormone, were restricted to the pituitary gland, thus indicative of pituitary-specific autoimmunity. Other proteins, like the La autoantigen, were systemic and detected in the absence of signs or family history of Sjögren syndrome. This "aberrant" and broad antigenic recognition could represent an early event in the pathway leading to the recruitment of tumor infiltrating lymphocytes by germinoma cells. Once homed to the germinoma site, the immune response could then spread to the organ/tissue harboring the germinoma (the pituitary gland in this case), secondarily causing organ-specific abnormalities (hypopituitarism in our patient).

In summary, we report a case of intra- and supra-sellar germinoma initially misdiagnosed as $\mathrm{AH}$, and provide insights to explain the lymphocytic infiltration typically seen in germinomas.

Acknowledgments This work was supported in part by NIH grant DK080351 to PC. The recombinant La protein was a gift of Dr. Felipe Andrade.

\section{References}

1. Packer RJ, Cohen BH, Cooney K (2000) Intracranial germ cell tumors. Oncologist 5:312-320

2. Jennings MT, Gelman R, Hochberg F (1985) Intracranial germcell tumors: natural history and pathogenesis. J Neurosurg 63:155-167

3. Matsutani M, Sano K, Takakura K, Fujimaki T, Nakamura O, Funata N, Seto T (1997) Primary intracranial germ cell tumors: a clinical analysis of 153 histologically verified cases. J Neurosurg 86:446-455

4. Lafay-Cousin L, Millar BA, Mabbott D, Spiegler B, Drake J, Bartels U, Huang A, Bouffet E (2006) Limited-field radiation for bifocal germinoma. Int J Radiat Oncol Biol Phys 65:486-492. doi:10.1016/j.ijrobp.2005.12.011

5. Utsuki S, Oka H, Tanizaki Y, Kondo K, Kawano N, Fujii K (2006) Histological features of intracranial germinomas not disappearing immediately after radiotherapy. Neurol Med Chir (Tokyo) 46:429-433. doi:10.2176/nmc.46.429

6. Caturegli P, Newschaffer C, Olivi A, Pomper MG, Burger PC, Rose NR (2005) Autoimmune hypophysitis. Endocr Rev 26:599614. doi:10.1210/er.2004-0011

7. Gellner V, Kurschel S, Scarpatetti M, Mokry M (2008) Lymphocytic hypophysitis in the pediatric population. Childs Nerv Syst 24:785-792. doi:10.1007/s00381-007-0577-1

8. Bettendorf M, Fehn M, Grulich-Henn J, Selle B, Darge K, Ludecke DK, Heinrich UE, Saeger W (1999) Lymphocytic hypophysitis with central diabetes insipidus and consequent panhypopituitarism preceding a multifocal, intracranial germinoma in a prepubertal girl. Eur J Pediatr 158:288-292. doi: $10.1007 / \mathrm{s} 004310051074$
9. Endo T, Kumabe T, Ikeda H, Shirane R, Yoshimoto T (2002) Neurohypophyseal germinoma histologically misidentified as granulomatous hypophysitis. Acta Neurochir (Wien) 144:12331237. doi:10.1007/s00701-002-1027-1

10. Fehn M, Bettendorf M, Ludecke DK, Sommer C, Saeger W (1999) Lymphocytic hypophysitis masking a suprasellar germinoma in a 12-year-old girl. A case report. Pituitary 1:303-307. doi:10.1023/A:1009923029942

11. Houdouin L, Polivka M, Henegar C, Blanquet A, Delalande O, Mikol J (2003) Pituitary germinoma and lymphocytic hypophysitis: a pitfall. Report of two cases. Ann Pathol 23:349-354

12. Kim G, Park SA, Hwang HJ, Lee JY, Ko SH, Ahn YB, Song KH (2007) A case of suprasellar germinoma misdiagnosed as lymphocytic hypophysitis. Korean J Med 73:210-215. doi:10.3343/ kjlm.2007.27.3.210

13. Mikami-Terao Y, Akiyama M, Yanagisawa T, Takahashi-Fujigasaki J, Yokoi K, Fukuoka K, Sakuma M, Miyata I, Fujisawa K, Oi S, Eto Y (2006) Lymphocytic hypophysitis with central diabetes insipidus and subsequent hypopituitarism masking a suprasellar germinoma in a 13-year-old girl. Childs Nerv Syst 22:1338-1343. doi:10.1007/s00381-006-0078-7

14. Ozbey N, Sencer A, Tanyolac S, Kurt R, Sencer S, Bilgic B, Turantan I, Molvalilar S (2006) An intrasellar germinoma with normal cerebrospinal fluid beta-HCG concentrations misdiagnosed as hypophysitis. Hormones (Athens) 5:67-71

15. Saborowski O, Radü EW, Medelowitsch A, Tolnay M, Kirsch EC (2007) Suprasellar germinoma masked by lymphocytic hypophysitis: a case report. Clin Neuroradiol 17:259

16. Torremocha F, Hadjadj S, Menet E, Menet E, Kas A, Bourgeois H, Levillain P, Bataille B, Marechaud R (2002) Pituitary germinoma presenting as a pseudotumoral lymphocytic hypophysitis in a man. Ann Endocrinol (Paris) 63:13-17

17. Lupi I, Broman KW, Tzou SC, Gutenberg A, Martino E, Caturegli P (2008) Novel autoantigens in autoimmune hypophysitis. Clin Endocrinol (Oxf) 69:269-278. doi:10.1111/j.13652265.2008.03180.x

18. Caturegli P, Lupi I, Landek-Salgado M, Kimura H, Rose NR (2008) Pituitary autoimmunity: 30 years later. Autoimmun Rev 7:631-637. doi:10.1016/j.autrev.2008.04.016

19. Mootha SL, Barkovich AJ, Grumbach MM, Edwards MS, Gitelman SE, Kaplan SL, Conte FA (1997) Idiopathic hypothalamic diabetes insipidus, pituitary stalk thickening, and the occult intracranial germinoma in children and adolescents. J Clin Endocrinol Metab 82:1362-1367. doi:10.1210/jc.82.5.1362

20. Konno S, Oka H, Utsuki S, Kondou K, Tanaka S, Fujii K, Yagishita S (2002) Germinoma with a granulomatous reaction. Problems of differential diagnosis. Clin Neuropathol 21:248-251

21. Saito T, Tanaka R, Kouno M, Washiyama K, Abe S, Kumanishi $\mathrm{T}$ (1989) Tumor-infiltrating lymphocytes and histocompatibility antigens in primary intracranial germinomas. J Neurosurg 70:81-85

22. Parker C, Milosevic M, Panzarella T, Banerjee D, Jewett M, Catton C, Tew-George B, Gospodarowicz M, Warde P (2002) The prognostic significance of the tumour infiltrating lymphocyte count in stage I testicular seminoma managed by surveillance. Eur J Cancer 38:2014-2019

23. Bentley AJ, Parkinson MC, Harding BN, Bains RM, Lantos PL (1990) A comparative morphological and immunohistochemical study of testicular seminomas and intracranial germinomas. Histopathology 17:443-449. doi:10.1111/j.1365-2559.1990. tb00766.x

24. Nouri AM, Hussain RF, Oliver RT, Handy AM, Bartkova I, Bodmer JG (1993) Immunological paradox in testicular tumours: the presence of a large number of activated T-cells despite the complete absence of MHC antigens. Eur J Cancer 29A:18951899. doi:10.1016/0959-8049(93)90545-Q 